\title{
Integrated Durability of Automobile Alternator Test System Design Based on LabVIEW
}

\author{
Wu Weibin ${ }^{1}$, Feng Yue ${ }^{1}$, Du Junyi ${ }^{1}$, Xu Pengbo ${ }^{1}$, Feng Yunlin ${ }^{1}$, Hong Tiansheng ${ }^{*},{ }^{1}$, Chen Jiewei ${ }^{1}$ \\ and Liu Luoshi ${ }^{2}$ \\ ${ }^{1}$ Key Laboratory of Key Technology for South Agricultural Machine and Equipment, South China Agricultural Universi- \\ ty, Guangzhou510642, China \\ ${ }^{2}$ TRIV Electronics Company, Guangzhou 510641, China
}

\begin{abstract}
New standards in the automotive industry highlighted the situation of the actual operation of the alternator and a variety of harsh environment simulation limit test. Using new standards in the automotive industry as a guide, this article presents a virtual instrument based on the durability of automobile generator integrated test system. The design adopt virtual instrument technology in designing the system, Graphic language, LabVIEW is applied in writing measure-control program. The system uses a lot of features on LABVIEW, including Data acquisition, control of serials port, etc. Test implementation uses the host computer via RS232 and RS485 communication port and the data acquisition card, NI PCI6221 , to control the frequency hybrid motor, temperature control box, electronic loads and other intelligent devices, and to simulate a variety of automotive alternator working conditions and real-time monitoring to monitor the status of generators. Using this system, two separate automobile alternators can be tested in terms of high-speed vehicle impact and high temperature durability test and electrical performance test and other tests at the same time. As a result, the generator speed measurement error is within $1 \%$, the control error is within $2 \%$, voltage and current measurement errors were within $0.5 \%$ and $0.4 \%$, which meets the requirements.
\end{abstract}

Keywords: Automobile alternator, data-acquisition, electrical characteristics, LabVIEW, test, Integrated durability.

\section{INTRODUCTION}

As a major essential of automobile parts, the automotive alternator not only provides power to the ignition coil and the electrical equipment, but also charges the battery for the car. Therefore, power generation stability and durability is extremely important, and it comes the need for a compliant performance test system integrated generator, the generator quality and functional testing. With the development of the automobile industry in China, recent years there were many different types of integrated and intelligent automotive generator test platform. These test platforms generally provide only general performance test function generator, low efficiency of the test, and the measurement is limited to the general environment. National Development and Reform Commission issued the "automotive alternator technology" conditions for industries QC/T 729-2005 as well as new standards developed by the Guangzhou Automobile Group. The alternator simulation tests and limit test put stress on actual operating conditions that require a variety of harsh environments. In this paper, referring to QC/T 729-2005 and QC/T 424-1999 and other industry standards are referred as a guide [1-6]. In order to improve the scalability automobile generator test system, accuracy and efficiency of the test objectives, a new automobile generator integrated durability test systems was put forward, mainly for the alternator

*Address correspondence to this author at the Wushan Road, Guangzhou, Postcard: 510642, China; Tel: 86-20-85282269;

E-mail: tshong@scau.edu.cn speed impact (emergency gear), high temperature durability, and comprehensive performance testing tasks.

\section{AUTOMOBILE GENERATOR INTEGRATED DU- RABILITY TEST SYSTEM DESIGN}

\subsection{Design of Test System}

The system test plan is to use the host computer via RS232 and RS485 communication port and a data acquisition card (NI PCI-6221) for mixed mode to control the variable frequency motor and the temperature box, electronic load and other smart devices to simulate various automotive alternator working condition, condition monitoring and realtime monitoring of the generator, while completing the highspeed impact of two separate automobile generators, hightemperature durability test and factory performance testing tasks [7]. To ensure the system not only can meet the technical specifications and standard requirements for testing, but also has high control precision and accuracy. System design technical parameters are shown in Table $\mathbf{1}$.

\subsection{Test System Hardware Structure}

The system hardware consists of five major components: a control cabinet, high and low temperature heat chamber, electronic load box, distribution cabinet, and water tower. The main structure and function probably are as follows $[8$, 9]. 
Table 1. System's technical parameters and accuracy.

\begin{tabular}{|c|c|c|c|}
\hline Physical & Measurement Accuracy & Control Accuracy & Control and Measuring Range \\
\hline \hline Speed Measurement & $\pm 1.0 \%$ & $\pm 2.0 \%$ & $0 \sim 21000 \mathrm{r} / \mathrm{min}$ \\
\hline Voltage Measurement & $\pm 0.5 \%$ & $\pm 1.0 \%$ & $0 \sim 60 \mathrm{~V}$ \\
\hline Current Measurement & $\pm 0.4 \%$ & $\pm 1.0 \%$ & $0 \sim 300 \mathrm{~A}$ \\
\hline
\end{tabular}

Control cabinet: play a role in the remote operation and monitoring. The system contains IPC, data acquisition card, LCD, inverter and its associated components, and electrical parts.

Temperature control box: To simulate the generator and the role of external environmental conditions. Enabling the temperature change from $-40{ }^{\circ} \mathrm{C}$ to $125{ }^{\circ} \mathrm{C}$ within $0.5 \mathrm{~h}$. And it communicates with IPC through RS485. On the whole, the temperature box contains three parts. The under part is made up of the bracket and inverter motor. The belt drive part, is open to simulate automobile generator status; the upper part containing the thermostat housing portion, thermostat cabinets containing fixtures, relevant leads, is enclosed, to simulate the automobile generator external environment. The control section contains a variety of high and low temperature heat cabinet components: air compressor, heater, cooling system, heat insulation systems, control systems, human machine interface.

Electronic load box: Programmable power load box, due to the relatively large size self-contained part, consumes the power from the alternator. It can choose the constant voltage, constant current mode of operation, etc. to communicate with the IPC through the RS232.

Distribution Cabinet: Distribution system for the electricity situation and has switch to protect the system's security.

Tower system: including the towers, piping, etc., mainly to provide the required cooling water for temperature control box.

Hardware structure and the relationships between the parts are shown in Fig. (1).

\section{TEST SYSTEM SOFTWARE DESIGN}

\subsection{Overall Structure of Software Design}

The system software has been design In LabVIEW 8.6 development platform. The whole structure is divided into four modules including the system parameter setting, equipment commissioning, endurance test and performance test of four modules. In the parameter setting module, the system can achieve global parameter settings. Device debug module provides hardware debugging. Durability test module realized work performance comparison before and after the durability test for the generator. In the performance test module can perform the electrical characteristics of the generator, by performing durability and other tests as needed.

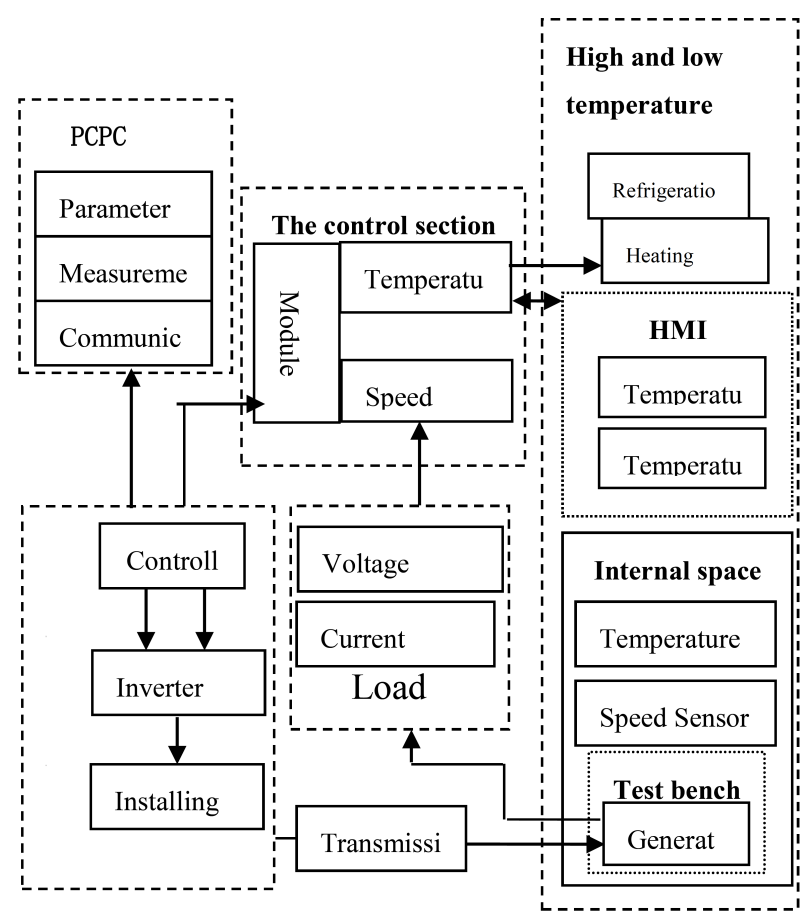

Fig. (1). Test system hardware structure.

\subsection{Durability Test Module}

\subsubsection{Modules Feature Requirements}

This module is based primarily on the Guangzhou Automobile AC alternator project technical specifications for the generator to test work durability. The test results are plotted in Figure Webber in the $350 \mathrm{~h}$. The overall test process is shown in Fig. (2).

\subsubsection{Durability Test}

Work includes four major endurance tests: temperature change durability testing, high-temperature durability testing, thermal and high-speed acceleration and maximum speed durability testing. When performing the combined cycle test, the test sequence of the four pilot projects can be sorted according to the requirements of each test cycle and project cycles. Test control flow is shown in Fig. (3).

In Fig. (4), the top of the interface is the setting section of the experiment. You can set the sort of the four endurance tests. In addition, you can click the button of "The parameter design for the sub experiment "to enter the sub interface, set electronic load (constant current, constant voltage or constant resistant) as well as its constant value and so on. 


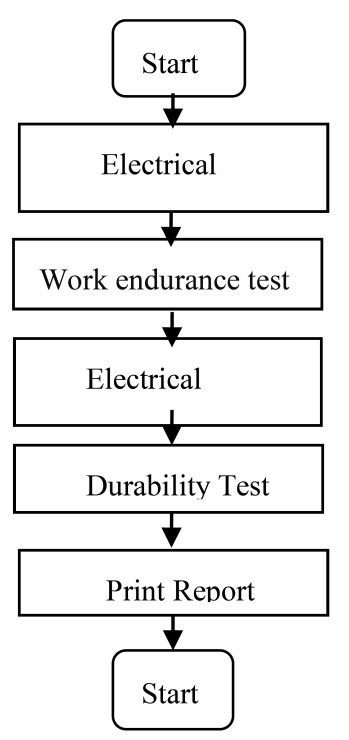

Fig. (2). Durability test procedures.

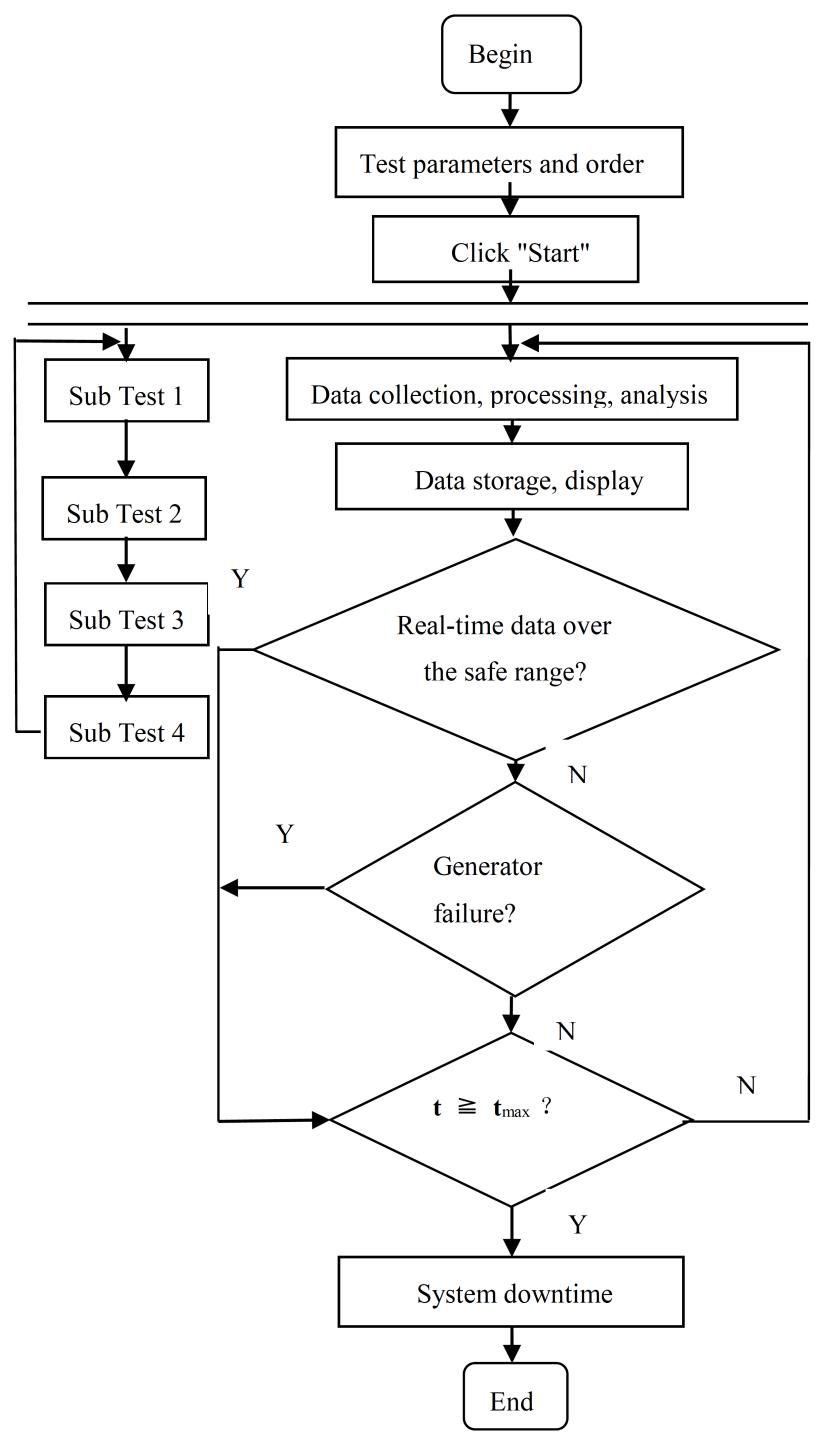

Fig. (3). Durability test work control process.
The middle and right interfaces are the numerical display section and the graphical display section. The system displays the data of the generator voltage, the battery voltage, the load voltage the generator current and the battery current in real time. Also, it can draw the curves of the generator speed, the voltage, the current and the temperature of the temperature controlled tank.

The lower half of the interface is the alarm display section. The system displays the running conditions of the generators on it in real time. When the collected data related to parameters is set in the alarm, the warning light or the stop light will be on and prompt the alarm reason. When the stop light is on, the system will be forced to stop.

During the experiment, if you want to review a long time (like 12 hours) of the changing process of system data, you can click "The playback of the historical data" and choose the Excel documents you need to view. The data will be read automatically and be shown in the oscillogram.

\subsubsection{Electrical Characteristics Test}

The experimental methods of the electrical characteristic test of electric generator are divided into the cold characteristic test, thermal characteristic test and driving power and efficiency characteristic test. The interface design is similar to durability test. The control flow of the test is shown in Fig. (5) [10-13].

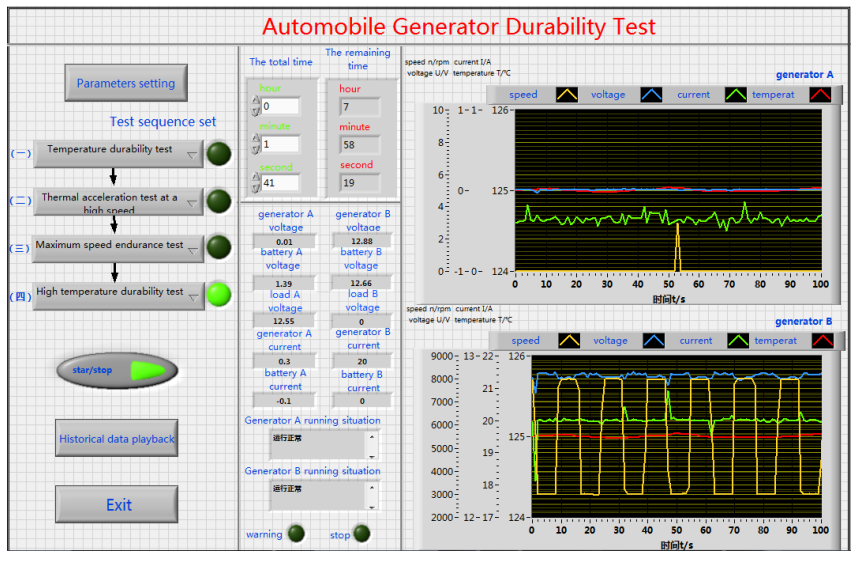

Fig. (4). Front panel of user interface.

\section{ACHIEVE TEST SYSTEM}

\subsection{System Control Principle}

System control principle is shown in Fig. (6). The IPC controls the inverter, temperature control box, load boxes and other hardware devices by the mixed mode of RS232 and RS485 communication port and LabVIEW acquisition card (PCI-6221). In addition, the inner control loop of the inverter and the controller of the temperature controlled tank greatly improve the control precision of the system .

\subsection{Pci-Daq Data Acquisition}

In this system, the host computer inputs and outputs ana$\log$ quantity and outputs digital quantity by PCI-6221 data acquisition card, for regulating the inverter speed, 
and collecting the experimental data of the voltage and current of electric generator and the voltage and current of the battery etc. Besides, it can use digital output to control the indicator light of hardware. The associated graphics code is shown in Fig. (7).

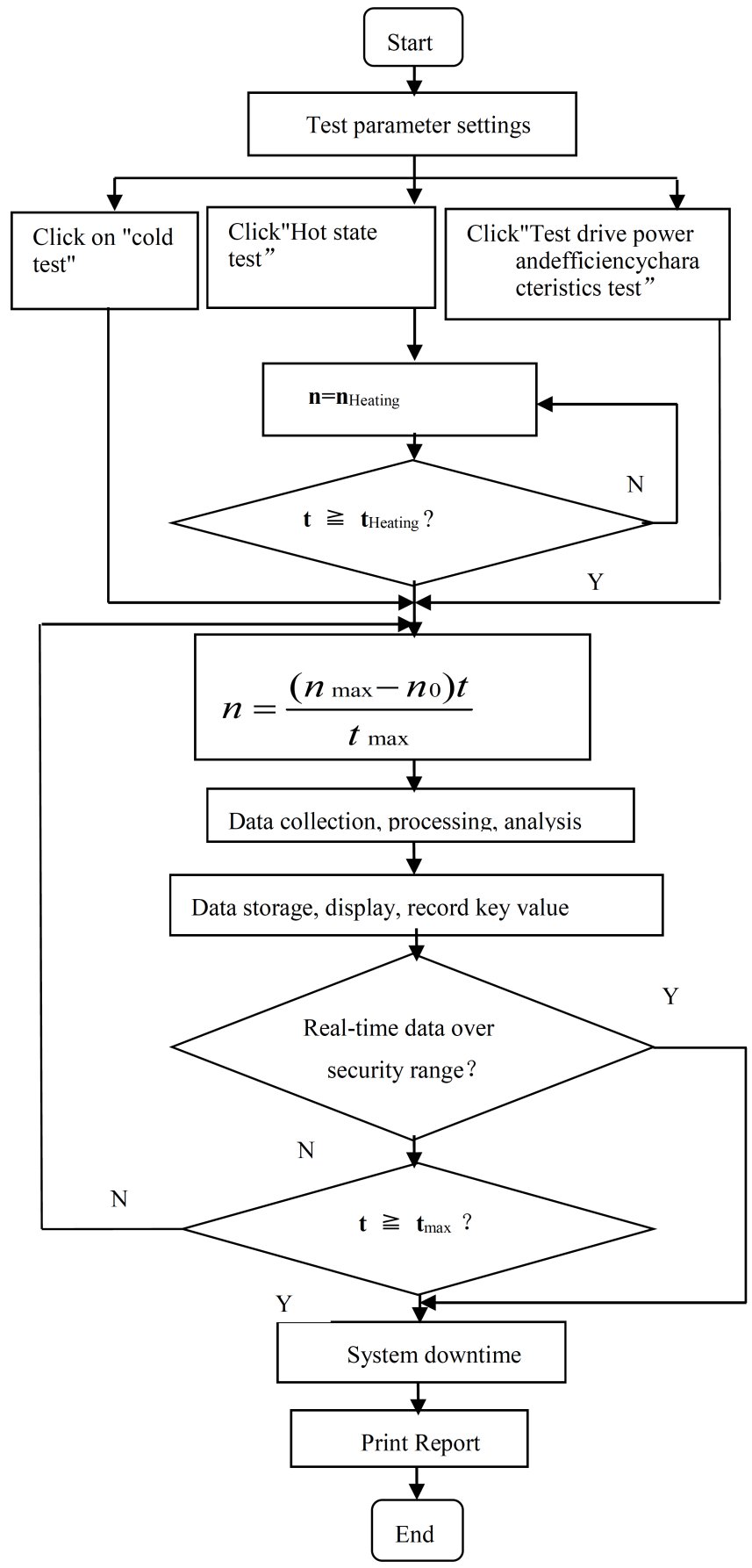

Fig. (5). The electrical characteristics of the test control flowchart.

The AI signals in this system are all converted into DC voltage signals by sensors and are collected by PCI-6221. The relationship between the resulting DC voltage and the measured analog is linear. According to the multiple of themeasured analog to the DC voltage, we can call the code of analog signals acquisition to get the DC voltage directly and restore the analog value by linear conversion.

\subsection{Serial Port Control for Temperature-ControlledBox and Electronic Load}

Both temperature-controlled box and DC electronic load use serial interface for communication. Since two devices don't have their own drivers, the design for control program which is involved in the internal control of the devices, uses a VISA function node. In addition, to facilitate control code reuse as well as system maintenance, we put the entire contents that are to control and measurement of the two devices for package on two separate devices in the control module, which is for the convenience of the main program calls. Because LabVIEW program is run in parallel mechanism, in order to prevent possible confusion during program execution, we have adopted a combination of loop structure and selection structures that were programmed in the two module devices. Furthermore, to enter a particular case, it depends on the number of the internal cycles as well as the necessary passing parameters. It is that, with the constant circulation, different instructions were transmitted to the device to control before its reading.

\section{SYSTEM ERROR WITH THE EXPERIMENTAL DATA ANALYSIS}

\subsection{System Error Analysis}

The system uses the sensors of speed, torque, current and voltage to measure the rotational speed of the generator, the generator torque, the generator voltage, voltage, generator current, and battery current. The control circuit controls the output voltage, the generator starts up and the output voltage makes the system work immediately. The physical quantity measured by the sensor is converted into a DC voltage by collecting data acquisition card, enabling real-time monitoring of the system.

Error Analysis Conclusion: The relative error measureement is always less than $1 \%$. When the rotational speed of the generator is controlled by less than 1000 $\mathrm{r} / \mathrm{min}$, the control error is large. When the speed was controlled at $1000 \mathrm{r} / \mathrm{min}$ and $3000 \mathrm{r} / \mathrm{min}$, the control error is between $2 \%$ and $10 \%$. What's more is that the control speed is greater than $3000 \mathrm{r} / \mathrm{min}$ and the control error is $2 \%$ or less.

Therefore, it can be considered as the control error within $2 \%$ since the speed control during the durability test was higher than $3000 \mathrm{r} / \mathrm{min}$. See Figs. $(\mathbf{8}, \mathbf{9})$.

The constantly increasing generator speed and the current, cause some interference in the physical quantity measuring system. But it is still able to accurately measure the voltage. And the current and the generator voltage as well as generator current has a measurement error of $0.5 \%$ and $0.4 \%$ or less, respectively. See Figs. $(\mathbf{1 0}, \mathbf{1 1})$.

\subsection{The Analysis Of Data Before and After the Durabil- ity Test}

\subsubsection{Variable Temperature Durability Test Data Shown in Table 2}

When the system temperature changed from $-40{ }^{\circ} \mathrm{C}$ to $125^{\circ} \mathrm{C}$ within $0.5 \mathrm{~h}$, it achieved current and voltage monitoring and control. 


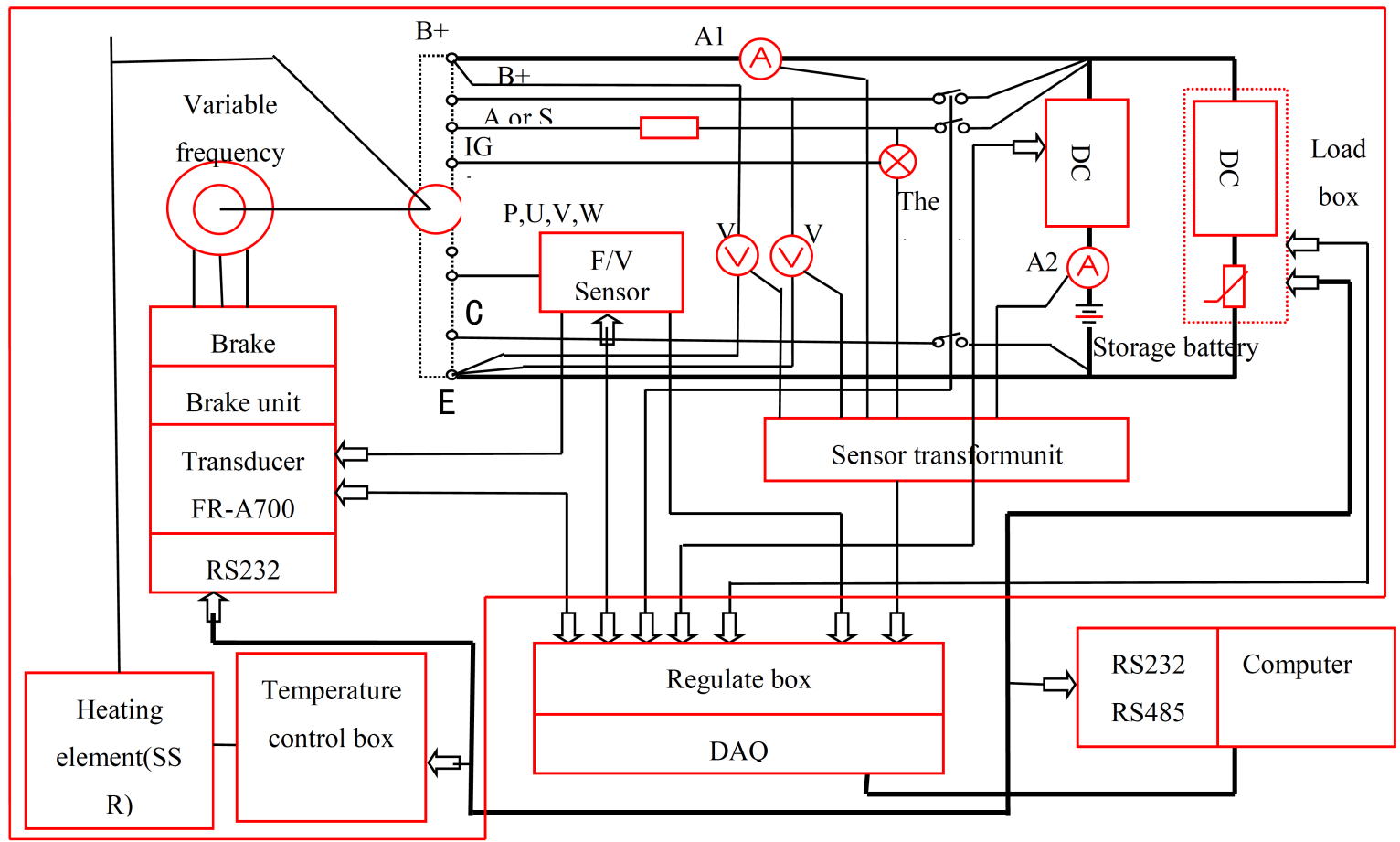

Fig. (6). Systems control theory.

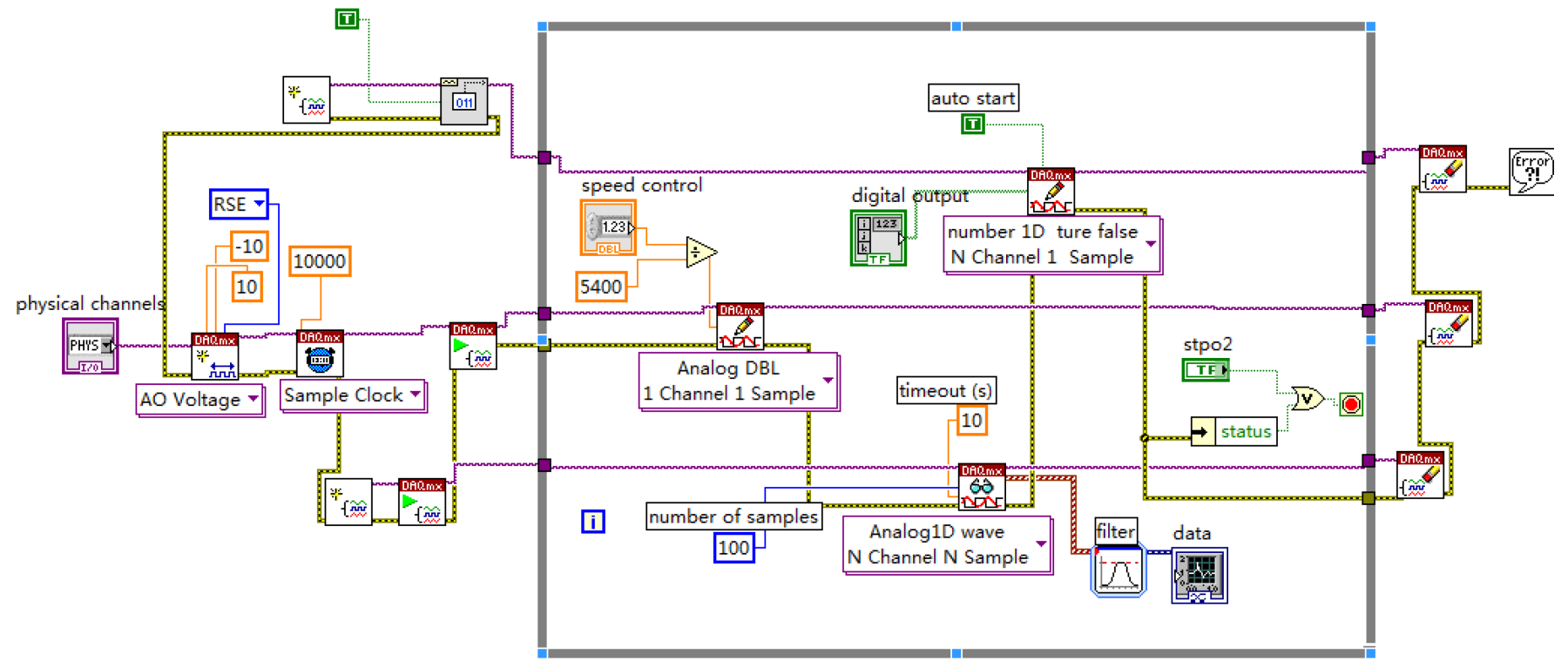

Fig. (7). PCI-6221 card, I / O Back panel of the program.

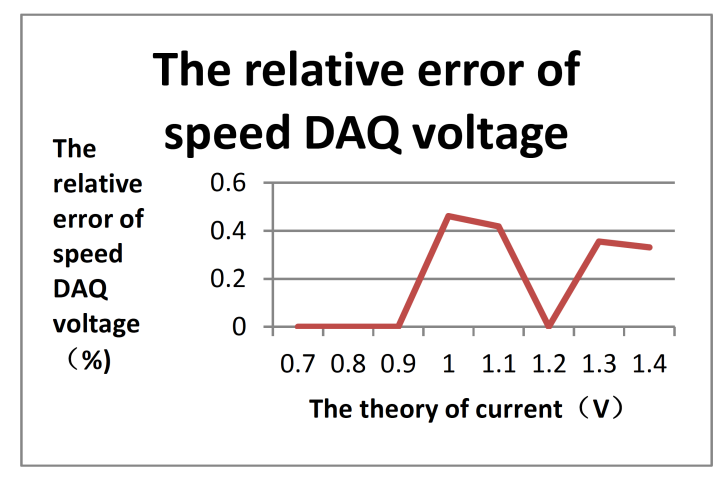

Fig. (8). Measurement error.

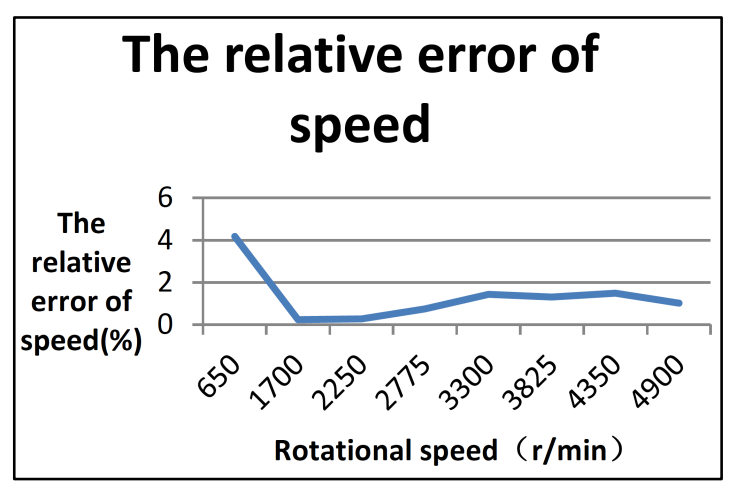

Fig. (9). Measurement error. 
Table 2. Variable temperature durability test data table.

\begin{tabular}{|cccccccc|}
\hline $\begin{array}{c}\text { Generator } \\
\text { Speed A/rmin }\end{array}$ & $\begin{array}{c}\text { Generator } \\
\text { Speed B/rmin }\end{array}$ & $\begin{array}{c}\text { Generator } \\
\text { Current A/A }\end{array}$ & $\begin{array}{c}\text { Generator } \\
\text { Current B/A }\end{array}$ & $\begin{array}{c}\text { Generator } \\
\text { Voltage A/V }\end{array}$ & $\begin{array}{c}\text { Generator } \\
\text { Voltage B/V }\end{array}$ & $\begin{array}{c}\text { Load } \\
\text { Voltage A/V }\end{array}$ \\
\hline \hline 0.00 & 0.00 & 0.00 & 0.00 & 12.64 & 12.73 & 11.94 \\
8065.93 & 8074.81 & 119.50 & 118.84 & 13.81 & 13.74 & 13.43 \\
8046.02 & 8049.37 & 116.56 & 117.12 & 13.72 & 13.73 & 13.28 \\
8092.12 & 8096.98 & 117.43 & 117.95 & 13.89 & 13.97 & 13.30 \\
8015.68 & 8010.80 & 118.15 & 118.53 & 13.83 & 13.77 & 13.53 \\
8099.74 & 8094.99 & 116.86 & 118.03 & 13.85 & 13.82 & 13.51 \\
\hline 0.00 & 0.00 & 0.00 & 0.00 & 12.58 & 12.71 & 13.31 \\
7998.12 & 8007.65 & 117.29 & 117.58 & 13.53 & 13.44 & 13.99 \\
8017.77 & 8014.03 & 117.48 & 117.33 & 13.63 & 13.51 & 13.19 \\
8007.13 & 8019.08 & 117.17 & 116.47 & 13.62 & 13.50 & 13.34 \\
7998.74 & 8004.62 & 118.00 & 116.45 & 13.69 & 13.62 & 13.21 \\
8006.48 & 8013.19 & 117.37 & 117.63 & 13.56 & 13.63 & 13.26 \\
\hline
\end{tabular}

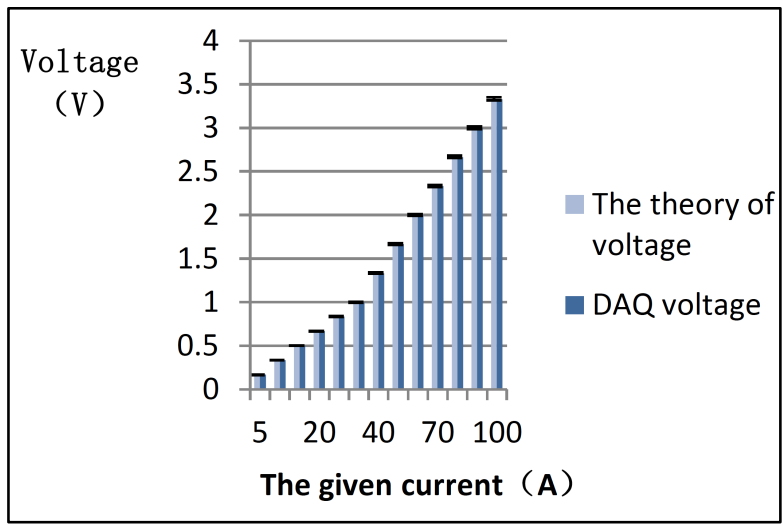

Fig. (10). Current error.

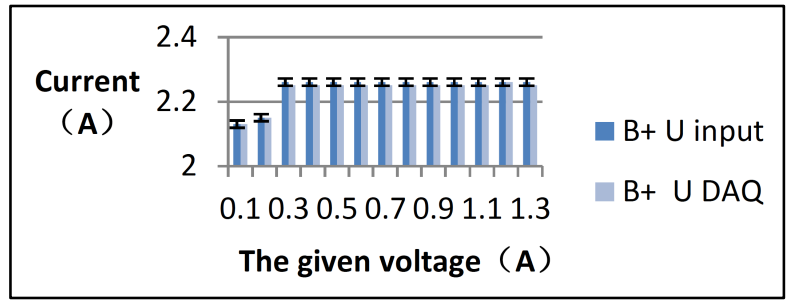

Fig. (11). Voltage error.

\subsubsection{Data before the Durability Test}

The generator electrical characteristics test has been taken before the durability test. Through the test, the current value can be obtained at the speed of $1800 \mathrm{r} / \mathrm{min}, 3000 \mathrm{r} / \mathrm{min}$ and $6000 \mathrm{r} / \mathrm{min}$. When it compares with the project of Guangzhou Automobile AC generator technical specifications, we can get the corresponding current standards are greater than $85 \mathrm{~A}, 120 \mathrm{~A}, 140 \mathrm{~A}$, as shown in Table 3.Therefore, it shows the electrical characteristics of the generator before the durability test qualified.

Table 3. System's thermal state and index before the test.

\begin{tabular}{|c|c|c|}
\hline Speed/rmin $^{-1}$ & Current Indicators /A & Electric Current /A \\
\hline \hline 1800 & $\geq 85$ & 90.32 \\
\hline 3000 & $\geq 120$ & 130.12 \\
\hline 6000 & $\geq 140$ & 143.01 \\
\hline
\end{tabular}

\subsubsection{Data After The Durability Test}

After durability test, the current value was obtained again by the curve at the speed of $1800 \mathrm{r} / \mathrm{min}, 3000 \mathrm{r} / \mathrm{min}, 6000$ $\mathrm{r} / \mathrm{min}$, the data were compared with before durability test, as shown in Table 4. It shows that the durability of the generator was qualified.

\section{CONCLUSION}

With this system, we can be more easily and accurately to put the two separate automotive alternators to have a durability test and other performance tests, including electrical properties, durability test. Speed measurement error is within $1 \%$ while the control error is within $2 \%$.

Table 4. System's thermal state and index after the test.

\begin{tabular}{|c|c|c|c|c|}
\hline Speed/rmi & Current Indicators /A & Electric Current /A & Electric Current /A & Reliability \\
\hline \hline 1800 & $\geq 85$ & 90.32 & 86.41 & 0.957 \\
\hline 3000 & $\geq 120$ & 130.12 & 128.03 & 0.984 \\
\hline 6000 & $\geq 140$ & 143.01 & 140.94 & 0.985 \\
\hline
\end{tabular}


What's more, the generator voltage and current in a measurement error of $0.5 \%$ and $0.4 \%$ or less, respectively, which meets the requirements.

\section{CONFLICT OF INTEREST}

The authors confirm that this article content has no conflict of interest.

\section{ACKNOWLEDGEMENTS}

This work was supported by the Guangzhou Science and Technology Project with the Serial Number of 2012J2200069, 2012J4200014.

\section{REFERENCES}

[1] G. Liu, "Automobile alternator test system hardware environment designGuangzhou," South China Agricultural University, 2010.

[2] X. Shen, "LabVIEW-based automotive alternator developed a comprehensive test bench Guangzhou," South China University of Technology, 2009.

[3] China Machinery Industry Association Education automotive electrical and electronic equipment Beijing: Mechanical Industry Press, 2003.
[4] People's Republic of China Automotive Industry Standard QC / T 729-2005, automotive alternator technical conditions The National Development and Reform Commission, 2005.

[5] People's Republic of China professional standards QC / T 424 1999, auto. China Automotive Industry Association alternator electrical characteristics of test methods, 1999.

[6] Guangzhou Automobile AC alternator project technical specifications," Guangzhou Automobile Group Automotive Engineering Research Institute proposed in, 2010.

[7] National Instruments Corp. LabVIEW Graphical Programming for Instrumentation, New York: National Instruments Corp. 1998.

[8] G. Hu, "utomotive electrical equipment structure and overhaul," Beijing: Mechanical Industry Press, 2007.

[9] Manan, VI of automobile generator based detection system Harbin: Harbin Engineering University, 2004.

[10] Q. Huang, Electrical Engineering Beijing: Higher Education Press, 2004.

[11] T. Hao, The basis of motor and drag Beijing: Mechanical Industry Press, 2004.

[12] Z. Kai, Z. Ping, and S. Yang, "Structural automotive alternator speed impact durability test system design," Auto Electric, no. 4 pp. 55-57, 2001.

[13] X. Ding, L. Zhao, and M. Liu, "Generator performance test platform based on virtual instruments," Computer Systems \& Applications, vol. 19, no. 9, pp. 143-146, 2010.

(C) Weibin et al.; Licensee Bentham Open.

This is an open access article licensed under the terms of the Creative Commons Attribution Non-Commercial License (http://creativecommons.org/licenses/by-nc/4.0/) which permits unrestricted, non-commercial use, distribution and reproduction in any medium, provided the work is properly cited. 